Çukurova Üniversitesi Mühendislik Mimarlık Fakültesi Dergisi, 31 (2), ss. 307-315, Aralık 2016

Çukurova University Journal of the Faculty of Engineering and Architecture, 31 (2), pp. 307-315, December2016

\title{
Kaplamalı Denim Kumaşlarda Performans Özellikleri Üzerine Deneysel Bir Çalışma
}

\author{
Füsun DOBA KADEM ${ }^{* 1}$, Şehpal TÖLEK ${ }^{1}$ \\ Çukurova Üniversitesi, Mühendislik Mimarlık Fakültesi, Tekstil Mühendisliği Bölümü, Adana
}

Geliş tarihi: 08.06.2016

Kabul tarihi: 23.11 .2016

$\ddot{O} z$

$\mathrm{Bu}$ çalışmada kaplamalı denim kumaşların performans özellikleri incelenmiştir. Referans numuneye kaplama işlemi uygulanmamıştır. Diğer numunelere kaplama yapılmıştır. Numunelerde atkı ipliği olarak Ne 13/ 1 pamuk $(\% 92,48)+78$ dtex elastan $(\% 7,52)$ içerikli iplikler kullanılmıştır. Çözgüde ise Ne 9,75/1 pamuk iplikleri kullanılmıştır. Kaplama metodu olarak tek yüze bıçakla kaplama metodu uygulanmıştır. Kaplamanın etkisini tespit edebilmek için kumaşlara kalınlık, kopma mukavemeti, hava geçirgenliği, su buharı direnci, boncuklanma, yumuşaklık gibi testler uygulanmıştır.Tek yüz kaplama işlemi performans özelliklerini kayda değer olumsuz bir şekilde etkilememiştir.

Anahtar Kelimeler: Su buharı direnci, Hava geçirgenliği, Kaplama, Denim

\section{An Experimental Study on Performance Properties of Coated Denim Fabrics}

\begin{abstract}
In this study, it is subjected to investigate performance properties of coated denim fabrics. Reference fabric was uncoated denim fabric and the other samples were coated fabrics. The warp thread of the fabrics was $\mathrm{Ne} 9,75 / 1$ cotton thread, and the weft thread was $\mathrm{Ne} 13 / 1$ cotton $(92,48 \%)$ and 78 dtex elastane $(7,52 \%)$. The roll on knife coating was chosen as the application method. In order to determine the effect of coating on performance properties, fabric thickness, tensile strength, air permeability, water vapor resistance, pilling, fabric stiffness etc. were achieved respectively for all denim fabrics. Evaluating the performance, single face coating process did not reveal significantly negative outcomes performance properties of fabrics.
\end{abstract}

Keywords: Water vapor resistance, Air permeability, Coating, Denim

\footnotetext{
*Sorumlu yazar (Corresponding author): Füsun DOBA KADEM, efsun72@cu.edu.tr
} 


\section{GíRiş}

Kaplamalı kumaş, en az biri tekstil yüzeyi ve en az biri polimerik tabaka olan 2 ya da daha fazla tabakanın birleşmesiyle oluşan yüzeydir. Ticari kapsamı incelendiğinde, kaplamalı kumaşların teknik tekstil ürünlerinde sıkça kullanıldığı görülmektedir [1].

Kaplama ve laminasyon, kumaşların fiziksel ve estetik özelliklerini geliştirmek ve değiştirmek, kumaşların, polimer, köpük ve filmlerin avantajlarını kombine ederek, kullanım alanını genişletmek amacıyla uygulanmaktadır [2].

Kaplamada amaç; polimer bir tabakanın bir tekstil dış yüzeyine nüfuz ederek fiziksel ve karakteristik özelliklerinin önemli bir şekilde değiştirilmesidir. Tekstil kaplamacılığı sayesinde kumaşı oluşturan lifler ile kazandırılmayacak özellikler, düzgün bir polimer maddenin mamule aktarılmasiyla kazandırılır [3]. İstenilen efekte göre s1v1, hamur veya toz halde bulunan kimyasallar toz, pasta veya köpük formunda kumaşa aktarılarak kumaş üzerinde bir film tabakası oluşturulmaktadır [4].

Orijinal kaplama metotlarının esasını, büyük çoğunlukla, alınan flotte miktarını ayarlayacak bir çift sıkma silindirinin bulunduğu emdirme teknelerinde emdirme, ardindan kuru sicak hava ortamında ve genellikle ramözde (germeli kurutucuda) sabit ende kurutma oluşturmaktadır. Ancak kaplamanın kumaşın tek bir yüzüne yapılması gerektiğinde, kumaşın tamamen kaplama flottesi içerisine daldırılması mümkün olmayıp bunun için başka teknikler de geliştirilmiştir. Kaplama direkt (direkt kaplama) ve dolaylı (transfer kaplama) olarak tekstil yüzeyine uygulanabilir [3].

Bir tekstil yüzeyini polimerik bir maddeyle kaplamak, zemin kumaşa yeni bir nitelik katar. Elde edilen kaplanmış kumaş ya su iticilik, hava geçirgenliği vb. fonksiyonel özellikler kazanır ya da uygulama öncesinden bütünüyle farklı ve estetik bir görünüme kavuşur. $\mathrm{Bu}$ görünüm farklılığına örnek olarak deri görünümlü kaplamalı kumaşlar verilebilir. Polimer malzemeyi tekstil yüzeyine tatbik etmenin çok çeşitli metotları vardır. $\mathrm{Bu}$ metotlar siniflandirılırken kaplama malzemesi formu, uygulama şekli ve kullanılan aparatlar baz alınabilir [5]. En sık karşılaşılan metotlardan bazıları Çizelge 1'de verilmişstir.

Çizelge 1. Kaplama yöntemleri [2]

\begin{tabular}{|c|c|c|}
\hline \multirow{5}{*}{$\begin{array}{c}\text { Kaplama } \\
\text { Maddesinin } \\
\text { Sıvı } \\
\text { Olduğu } \\
\text { Kaplama } \\
\text { Metotları }\end{array}$} & \multirow{2}{*}{$\begin{array}{c}\text { Kaplama } \\
\text { Maddesinin } \\
\text { Sonradan } \\
\text { Dozajlandığ1 } \\
\text { Metotlar }\end{array}$} & $\begin{array}{l}\text { Biçakl1- } \\
\text { Rakleli- } \\
\text { Kaplama }\end{array}$ \\
\hline & & $\begin{array}{l}\text { Tel Sarılı } \\
\text { Rulo ile } \\
\text { Kaplama }\end{array}$ \\
\hline & \multirow{3}{*}{$\begin{array}{c}\text { Kaplama } \\
\text { Maddesinin } \\
\text { Önceden } \\
\text { Dozajlandığı } \\
\text { Metotlar }\end{array}$} & $\begin{array}{c}\text { Silindir ile } \\
\text { Kaplama }\end{array}$ \\
\hline & & $\begin{array}{c}\text { Döner Şablon } \\
\text { ile Kaplama }\end{array}$ \\
\hline & & $\begin{array}{c}\text { Püskürtme ile } \\
\text { Kaplama }\end{array}$ \\
\hline \multirow{4}{*}{$\begin{array}{c}\text { Kaplama } \\
\text { Maddesinin } \\
\text { Katı } \\
\text { Olduğu } \\
\text { Kaplama } \\
\text { Metotları }\end{array}$} & \multirow{2}{*}{$\begin{array}{c}\text { Sicak Eriyik ile } \\
\text { Kaplama }\end{array}$} & $\begin{array}{l}\text { Ekstrüzyon } \\
\text { ile Kaplama }\end{array}$ \\
\hline & & $\begin{array}{l}\text { Pudralı } \\
\text { Kaplama }\end{array}$ \\
\hline & \multicolumn{2}{|c|}{ Kalandır ile Kaplama } \\
\hline & \multicolumn{2}{|c|}{ Transfer Kaplama } \\
\hline Modern & \multicolumn{2}{|c|}{ Sol-jel ile Kaplama } \\
\hline Yöntemleri & \multicolumn{2}{|c|}{ Plazma ile Kaplama } \\
\hline
\end{tabular}


Silindir üstü bıçak kaplama yöntemi, hassas çalışma imkanı sağlaması ve basit bir uygulama olması sebebiyle en önemli ve geniş uygulama alanı bulmuş teknolojidir.

Şekil 1'de bıçaklı (rakleli) kaplama metodu gösterilmiştir. $\mathrm{Bu}$ metotta ayarlı şekilde konumlanmış sıyırıcı bıçak, silindir üzerine yerleştirilmiştir. Kaplama miktarı, bu bıçak ve silindir arası mesafe ile ayarlanmaktadır. Silindir, kauçuk veya çelik olabilmektedir. Kullanılan zemin kumaşa bağlı olarak 60-90 shore sertlikteki silindirler daha çok tercih edilmektedir. Kauçuk silindirler genellikle kumaş üzerinde düğüm, şantuk gibi düzgünsüzlükleri göstermediği, absorbe edebildiği için avantajlı sayılmaktadır [5].

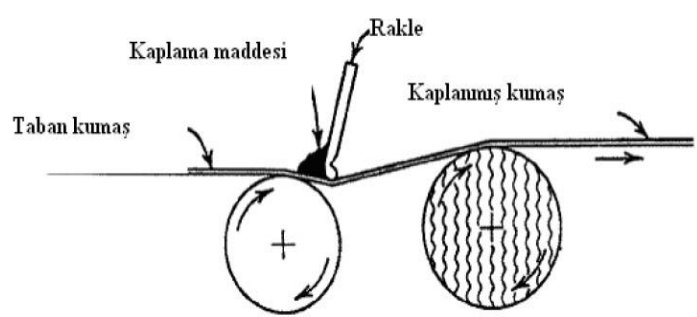

Şekil 1. Bıçaklı (rakleli) kaplama metodu [2]

Kaplama kumaşların kullanım yerine ve amacına uygun olan fonksiyonel özellikleri; kaplama maddesinin yapısına, tekstil yüzeyinin yapısı ile özelliklerine ve uygulanan kaplama tekniğine göre değişkenlik gösterebilmektedir.

\section{2. ÖNCEKİ ÇALIŞMALAR}

Kaplama; geçmişten günümüze kadar kullanımı olan, ve hızla gelişen bir sektördür. Son yıllarda; tekstil terbiye sinıflandırılmasında, ön terbiye, boya- baskı ve bitim işlemlerinin yanında kaplama da ayrica bir sinıf altında incelenmektedir. Kaplama işlemi özellikle, teknik tekstiler sektöründe oldukça geniş bir kullanıma sahiptir. Yeni gelişmeler ve araştırmalar 1şı ğında kaplama ürünlerin performans özellikleri de gelişmekte ve sonuç olarak da bu ürünlerin kullanım alanları genişlemektedir. Kaplama gerek kullanılan yapıştırıcı maddelerin alternatiflerinin çokluğu, gerekse aplikasyonda kullanılan makineleriyle geniş bir sektör oluşturmakta ve tekstilde yeni alternatif ürünlerin doğmasına katkıda bulunmaktadır [5].

Kut ve Güneşoğlu [4], bezayağ1 örgü \%100 PES dokuma kumaşa poliüretan ve poliakrilat kaplama işlemi uygulanmış, kopma mukavemeti, aşınma direnci, su geçirmezlik vb. çeşitli performans özelliklerindeki değişimler değerlendirilmiştir. Ayrıca kaplama sonrası renk değişimleri değerlendirilmiştir. Sonuçlara göre, kaplamanın kumaşın kopma mukavemetini arttırdığı, en yüksek artışın poliüretan kaplama kumaşlarda olduğu belirlenmiştir. Poliüretan ve poliakrilat kaplama kumaşlarda aşınma direnci açısından pek fark olmadığı ve ayrıca poliakrilat kaplama kumaşın su geçirmezlik performansının en yüksek olduğu görülmüştür. Poliüretan kaplamanın kumaşta yüksek renk farkına neden olduğu gözlenmiştir.

Kaplama kumaşların kullanım alanları ve özelliklerinin değerlendirildiği bir çalışmada Kaplan ve Koç [6], kaplama kumaşların dünyadaki durumu ile ilgili istatistiksel veriler sunmuşlardır. Bu çalışma ile kaplama kumaş özelliklerini önemli derecede etkileyen parametrelerden biri olan kumaş kaplama metodları, söz konusu metodlara uygun kaplama maddesi özellikleri ve bu metodlarla elde edilen mamullerin kullanım alanları ayrıntılı olarak incelenmiştir.

Yeşilalan ve arkadaşları [7], yaptıkları deneysel ve teorik çalışmada bazı kaplama parametrelerini değişken olarak kabul edip bir modelleme geliştirmişlerdir. Uygulamada kullanılan kaplama malzemesi poliüretandır. Hazırlanan patın penetrasyonunun tahminlenmesi hedeflenen çalışma sonucunda, kaplama kalınlığı ve bazı fiziksel performans değerleri de parametre olarak belirlenmiştir.

Padleckiene ve Petrulis [8], yaptıkları çalışmada poliüretan nefes alabilir kaplama malzemesi kullanarak kaplanmış kumaşın tekrarlı esnetme işlemleri sonucunda hava geçirgenlik değerlerindeki değişimleri incelemiş, bir korelasyon analizi yapılmıştır. 
Şahin [9], farklı kumaşlara (mikro PES, PA, PES, PES/PA) farklı yüzdelerde poliüretan kaplama uygulamış ve bu kumaşların su geçirmezlik ve mukavemet performans özelliklerini tespit etmiştir. Metot olarak silindir üzeri kaplama metodu uygulanmıştır. Su geçirmezlik test sonuçları karşılaştırıldığında mikro PES kumaşın işlem görmemiş haliyle $70 \mathrm{~g}$ PU kaplanmış hali arasında 70 katlık bir artış gözlenmiştir. PU ile kaplanmış kumaşların \% uzama değerlerine bakıldığında kumaşlarda mikro PES kumaş dışında genel olarak daha çok çözgü yönünde olmak üzere her iki yönde de düşme gözlenmiştir. Mukavemet değerleri incelendiğinde PA kumaşta, PU yüzdesinin miktarındaki artışa bağlı olarak atkı ve çözgü yönünde azalma gözlenmiştir. Mikro PES ve PES kumaşta ise PU miktarı artıkça, hem atkı hem de çözgü yönünde artış görülmüştür.

Yang ve Wei-dong [10], poliüretan kaplama malzemesiyle 4 farklı materyalden üretilmiş dokuma kumaşların üretim parametrelerinin performans özelliklerine etkilerini incelemişlerdir.

Bu deneysel çalışmada, işletme şartlarında tek yüz silindir üstü bıçak kaplama tekniği kullanılarak bir referans zemin kumaş üzerine 3 farklı renk ve içerikte kaplama uygulaması yapılarak 4 adet numune elde edilmiştir. Bu numunelerin kaplama reçetelerindeki boyarmaddeler ve kimyasallar detaylı olarak açıklanmıştır. Zemin kumaşı aynı olan 4 numune, kaplama işlemi sonrası aynı terbiye işleminden geçerek üretimi tamamlanmıştır. Daha sonra elde edilen numunelere bazı performans testleri uygulanmıs, kaplamanın ve kaplama reçetesindeki kimyasal ve boyarmadde farklılıklarının performans özelliklerine etkisi değerlendirilmiştir.

\section{MATERYAL VE METOT}

\subsection{Materyal}

Çalışmada \%100 pamuklu denim kumaşa kaplama yapmak üzere ön terbiye işlemleri işletme şartlarında gerçekleştirilmiştir. Kumaş atkıda $\mathrm{Ne}$ 13/1, çözgüde ise Ne 9,75/1 ring ipliği kullanılarak dokunmuştur. Denim kumaş, klasik denim üretim prosesine tabi tutulmuştur. Ön terbiyesinde sırasıyla yakma, pişirme, merserizasyon ve ağartma prosesleri uygulanmıştır. Çizelge 2 ve Çizelge 3 deneysel çalışmada kullanılan denim kumaşın fiziksel özellikleri ve denime uygulanan terbiye-kaplama işlemlerini göstermektedir.

Çizelge 2. Denim kumaşın fiziksel özellikleri

\begin{tabular}{|c|c|}
\hline Parametreler & Kumaş Özellikleri \\
\hline Çözgü İpliği (Ne) & $9,75 / 1 \mathrm{CO}$ \\
\hline Atkı İpliği (Ne) & $\begin{array}{c}13 / 1 \\
\mathrm{CO}(\% 92,48)+\mathrm{EA}(\% 7,52)\end{array}$ \\
\hline Örgü Tipi & $3 / 1 \mathrm{Z} \mathrm{Dimi}$ \\
\hline $\begin{array}{c}\text { Dokuma } \\
\text { parametreleri }\end{array}$ & $\begin{array}{c}\text { Tarak no:56/4 } \\
\text { Tarak eni:195 cm } \\
\text { Äzgü siklı̆̆ } 1: 32 \mathrm{tel} / \mathrm{cm} \\
\text { Atk1 sılı̆ı̆1:16 atk1/cm }\end{array}$ \\
\hline $\begin{array}{c}\text { Kumaş } \\
\text { Kompozisyonu }\end{array}$ & $97 \% \mathrm{CO}+3 \% \mathrm{EA}$ \\
\hline
\end{tabular}

Çizelge 3. Denim kumaşta terbiye ve kaplama

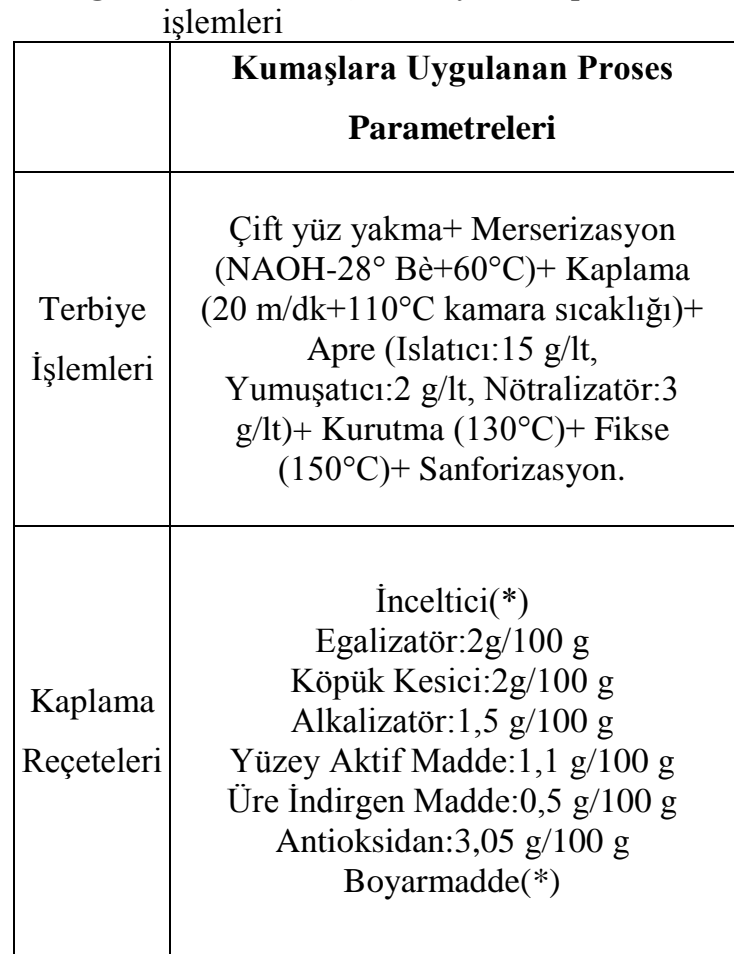

(*) Çizelge 4'te miktarları verilmiştir. 


\subsection{Metot}

Çalışmada kullanılan \%97 pamuk \%3 elastan içeren bir zemin kumaş üzerine 3 farklı reçete ile tek yüz üzerine silindir üzeri bıçak kaplama tekniğiyle kaplama işlemi uygulanmıştır.

Toplamda kaplamasız kumaş ile birlikte 4 farklı numune, seçilmiş bir işletmede üretilmiştir. Kumaşların fiziksel ve performans özellikleri standartlara göre test edilmiş ve sonuçları değerlendirilmiştir.

Kaplama işlemi yapılırken hazırlanan reçeteler arasında, kullanılan kimyasallardan sadece boyarmadde ve inceltici maddenin farklılıkları vardır. İşletme şartlarında, müşteri talepleri doğrultusunda elde edilmek istenen renk tonuna göre hazırlanan bu reçetelerdeki inceltici maddeler, boyarmadde miktarı ve istenen renk tonuna göre ayarlanmaktadır. Diğer tüm kimyasallar tür ve miktar olarak aynıdır. Çizelge 4'te miktarlar ve boyarmaddeler belirtilmiştir.

Çizelge 4. Kaplama reçetelerindeki kimyasallar

\begin{tabular}{|c|c|c|c|}
\hline \multirow{2}{*}{$\begin{array}{c}\text { Numune } \\
\text { Ad } 1\end{array}$} & \multirow{2}{*}{$\begin{array}{c}\text { İnceltici } \\
(\mathrm{G})\end{array}$} & \multicolumn{2}{|c|}{ Boyarmadde } \\
\hline & & Ad1 & $\operatorname{Miktar} 1(\mathrm{G})$ \\
\hline \multirow{2}{*}{$\mathrm{K} 1$} & \multirow{2}{*}{87,47} & $\begin{array}{c}\text { Diresul } \\
\text { Olive }\end{array}$ & 2 \\
\hline & & $\begin{array}{l}\text { Diresul } \\
\text { Brown }\end{array}$ & 0,38 \\
\hline $\mathrm{K} 2$ & 83,85 & $\begin{array}{c}\text { Diresul } \\
\text { Blue }\end{array}$ & 6 \\
\hline \multirow{2}{*}{$\mathrm{K} 3$} & \multirow{2}{*}{88,5} & $\begin{array}{c}\text { Diresul } \\
\text { Black }\end{array}$ & 1,2 \\
\hline & & $\begin{array}{c}\text { Diresul } \\
\text { Blue }\end{array}$ & 0,15 \\
\hline
\end{tabular}

Kaplama uygulamasında genellikle belirlenen bir zemin kumaş referans alınır ve kaplama prosesi bu zemin kumaş üzerine gerçekleştirilir. Dolayısıyla bu zemin kumaşın metrekare ağırlığı, kalınlık, sıklık gibi temel yapısal özellikler önem taşıdığı için numunelernin proses sonrası fiziksel özelliklerinden kumaşların gramaj tayini [11], kumaş kalınlığı tayini [12] ve kaplanmış kumaşların atkı ve çözgü yönlerindeki sıklık tayini [13] testleri yapılmıştır. Bunların yanında kaplamanın etkilerini tespit edebilmek için performans özellikleri test edilmektedir. Bu çalışmada kaplama kumaşlara uygulanan testlere ilişkin bilgiler ve ilgili standartlar Çizelge 5'te verilmiştir. Aşınma dayanımı tayininde 50.000 devire kadar deney yapılmıştır (Ağırlık: 595 \pm , Anma basinc1: $9 \mathrm{kPa}$ ).

Çizelge 5. Çalışmada esas alınan standartlar

\begin{tabular}{|c|c|c|}
\hline $\begin{array}{c}\text { Uygulanan } \\
\text { Test }\end{array}$ & Standart No & $\begin{array}{c}\text { Kullanılan } \\
\text { Cihaz }\end{array}$ \\
\hline $\begin{array}{c}\text { Su Buharı } \\
\text { Direnci }\end{array}$ & $\begin{array}{c}\text { TS EN } \\
\text { ISO } \\
\text { 2014 [14] }\end{array}$ & $\begin{array}{c}\text { SDL Atlas, } \\
\text { M259B-3 }\end{array}$ \\
\hline $\begin{array}{c}\text { Dairesel eğme } \\
\text { test metodu ile } \\
\text { kumaş }\end{array}$ & D 4032-94 & Pnömatik \\
yumuşaklığ1 & {$[15]$} & Sertlik Ölçüm \\
tayini & Cihaz1 \\
\hline Aşınma & TS EN ISO & SDL ATLAS, \\
Dayanımı & $12947-2:$ & M235 \\
\hline Boncuklanma & TS EN ISO & SDL ATLAS, \\
Tayini & $12945-2:$ & M235 \\
\hline Kopma & $2002[17]$ & TS EN ISO \\
Mukavemeti & $13934-$ & Titan \\
\hline
\end{tabular}

Su buharı direnci testinde temas yüzeyi arka yüz olacak şekilde hazırlanan numuneler standartta belirlenen şekilde teste tabi tutulmuş ve test sonuçları $\mathrm{m}^{2} \mathrm{~Pa} / \mathrm{W}$ cinsinden hesaplanmıştır. Kumaşlarda yüzey tüylenmesi ve boncuklanma 
yatkınlığının tayininde standarda uygun numuneler hazırlanmış ve 7000 devirde değerlendirilmiştir. Kumaş kalınlığı ölçümünde numunelere 5'er g ağırlık yüklenmiş olup baskı alanı $20 \mathrm{~cm}^{2}$ 'dir. Kopma mukavemeti tespit edilirken atkı ve çözgü yönünde 5'er numune hazırlanmış, bu değerlerin ortalaması alınarak sonuçlar elde edilmiştir. Kumaşların yumuşaklığı Stiffness cihazında ölçülerek bulunmuştur.

\section{BULGULAR VE DEĞERLENDİRME}

Deneysel çalışmada kullanılan kaplama malzemesi poliüretandır. Poliüretan (PU) her ne kadar güneş 1şı̆̆ına karşı çok dayanıklı olmasa da, hava şartlarına, aşınmaya, yırtılmaya dayanıklı bir malzeme olması nedeniyle özellikle fonksiyonel ürünlerde kaplama ya da laminasyon malzemesi olarak sıklıkla kullanılmaktadır. PU kaplamaların yaygın olarak kullanıldığı yerlere su geçirmez ve nefes alabilir kumaşlar, üniformalar, denim gibi moda ile sürekli değişen ve gelişen giysilik ürünler örnek verilebilir.

$\mathrm{Bu}$ çalışmada kullanılan kumaşlara yapılan testler sonucu elde edilen bulgular Çizelge 6, Çizelge 7 , Çizelge 8 ve Çizelge 9'da verilmiştir.

Çizelge 6. Denim kumaşların fiziksel özellikleri

\begin{tabular}{|c|c|c|c|c|}
\hline & \multirow{2}{*}{$\begin{array}{c}\text { Gramaj } \\
\left(\mathrm{g} / \mathrm{m}^{2}\right)\end{array}$} & $\begin{array}{c}\text { Kalınlı } \\
(\mathrm{mm})\end{array}$ & \multicolumn{2}{|c|}{ S1klık (tel/cm) } \\
\cline { 4 - 5 } & & & Atk1 & Çözgü \\
\hline Zemin & 340 & 0,61 & 19 & 34 \\
\hline K1 & 351 & 0,55 & 19 & 33 \\
\hline K2 & 350 & 0,56 & 19 & 34 \\
\hline K3 & 349 & 0,56 & 19 & 32 \\
\hline
\end{tabular}

Çizelge 7'de kaplamalı kumaşların su buharı direnci ve yumuşaklık sonuçları değerlendirildiğinde kaplamasız zemin kumaşın daha yumuşak ve daha iyi su buharı geçirgenliğine sahip olduğu, kaplama işlemiyle denim kumaşların yumuşaklığının azaldığı ve su buharına daha dirençli olduğu tespit edilmiştir.

4 kumaşın da boncuklanma değeri kabul edilebilir seviyede olup, kaplama ile boncuklanmaya karş1 iyileşme görüldügü sonuçlardan da söylenebilir 
Çizelge 8. Kaplamalı kumaşlarda aşınma ve

\begin{tabular}{|c|c|c|}
\hline & Boncuklanma & $\begin{array}{l}\text { Aşınma } \\
\text { Durumu }\end{array}$ \\
\hline Zemin & $3-4$ & \multirow{4}{*}{$\begin{array}{c}50.000 \text { devire } \\
\text { kadar aşınma } \\
\text { gözlemlenmemiştir }\end{array}$} \\
\hline K1 & 4 & \\
\hline $\mathrm{K} 2$ & 5 & \\
\hline K3 & 4 & \\
\hline
\end{tabular}

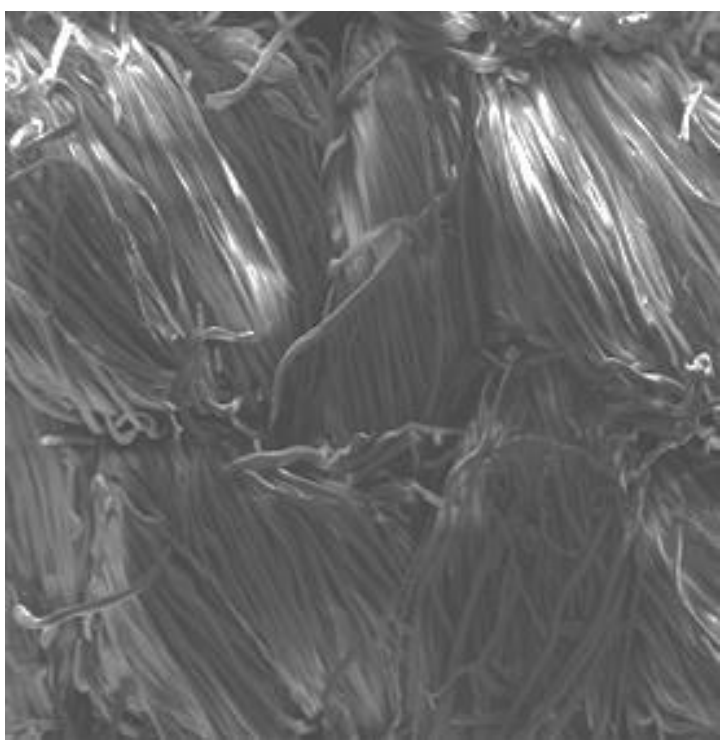

Şekil 3. Zemin kumaş numunesi SEM görüntüsü

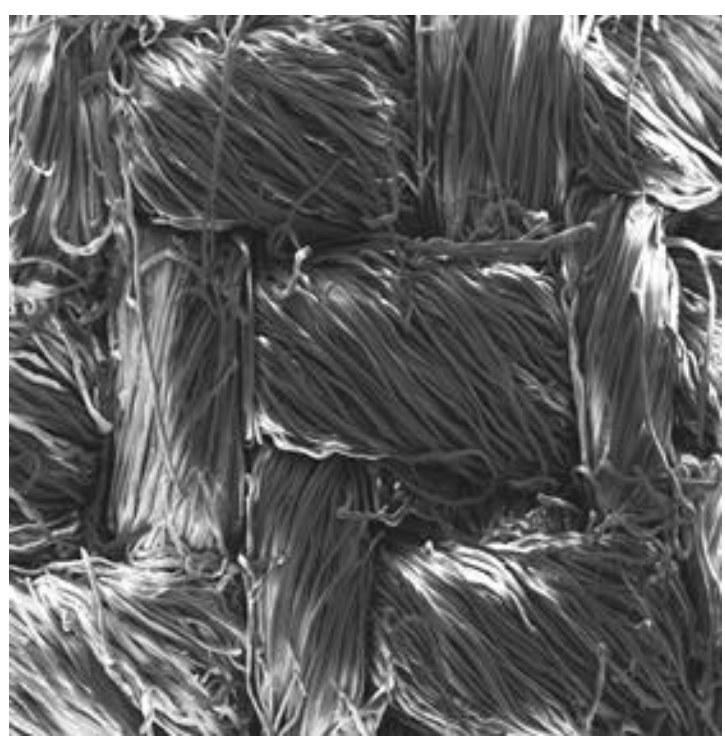

Şekil 4. K1 numunesi SEM görüntüsü
Zemin ve kaplamalı kumaşların yüzey özellikleri SEM cihazında (x200 büyütme oranı) incelenmiş olup Şekil 3, Şekil 4, Şekil 5 ve Şekil 6'da gösterilmektedir.

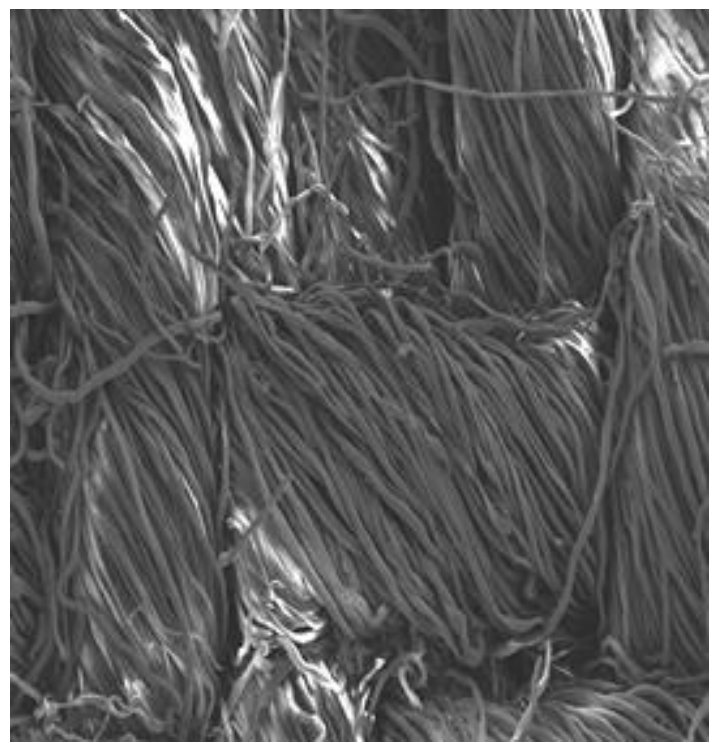

Şekil 5. K2 numunesi SEM görüntüsü

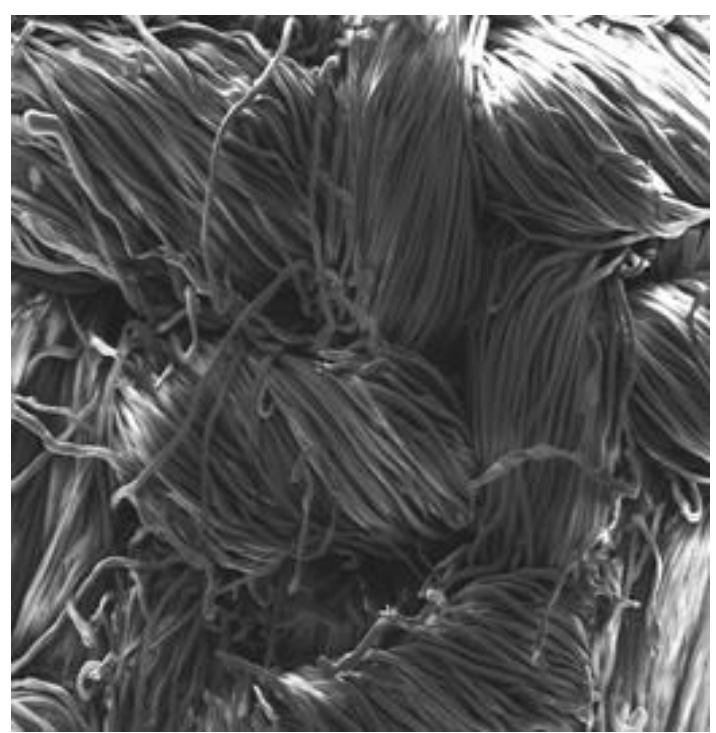

Şekil 6. K3 numunesi SEM görüntüsü

Şekillerden kaplamalı kumaşların uygulanan kaplama işlemi neticesi yüzey özelliğinin zemin 
kumaşla benzer düzgünlükte olduğu, Dimi örgü yapısının korunduğu anlaşılmaktadır.

Çizelge 9. Kaplamalı kumaşlarda kopma mukavemeti testi sonuçları

\begin{tabular}{|c|c|c|c|}
\hline \multirow{2}{*}{ Zemin } & & $\begin{array}{c}\text { Ortalama } \\
(\mathrm{N})\end{array}$ & Standart Sapma \\
\hline \multirow{2}{*}{ K1 } & Atk1 & 349,73 & 6,77 \\
\cline { 2 - 4 } & Çözgü & 1246,44 & 7,93 \\
\cline { 2 - 4 } & Atk1 & 404,67 & 7,44 \\
\hline \multirow{2}{*}{ K2 } & Çözgü & 1522,46 & 1,24 \\
\cline { 2 - 4 } & Atk1 & 394,34 & 3,26 \\
\hline \multirow{2}{*}{ K3 } & Atözgü & 1155,19 & 13,09 \\
\cline { 2 - 4 } & Çözgü & 413,39 & 3,97 \\
\hline
\end{tabular}

Çizelge 9'daki kopma mukavemeti sonuçlarına bakıldığında genel olarak tüm kumaşlarda çözgü kopma mukavemeti atkı kopma mukavemetinden daha yüksektir. Bu beklenen bir durumdur. Ayrıca kaplamalı kumaşların hem atkı hem çözgü kopma dayanımları zemin kumaşın atkı ve çözgü kopma dayanımlarına göre genel olarak yüksek çıkmıştır. Literatürde bu sonucu destekleyen çalışmalar bulunmaktadır.

\section{SONUÇ}

$\mathrm{Bu}$ çalışma kapsamında, aynı zemin kumaş üzerine, farklı reçete ölçülerinde hazırlanmış 3 renk kaplama reçetesinin kumaşların özelliklerine olan etkisi incelenmiştir. Seçilmiş bir işletmede, biri zemin kumaş olmak üzere toplam 4 numune üretilmiştir. Kaplamalı kumaşlar ile zemin kumaşların bazı özellikleri kıyaslanmıştır.

Elde edilen sonuçlara bakıldığında literatürde yapılmış çalışmalarla benzer sonuçlara ulaşılmıştır.

- Kaplamanın zemin kumaşın metrekare ağırlığını arttırdığı görülmüştür. Bu durum beklenen bir neticedir.

- Kaplama işlemi, zemin kumaşın kalınlığını azaltmıştır. Buna kaplama işleminin, kumaş yüzeyinde bulunan ve kumaşın yapısal özelliklerinden kaynaklanan kalınlık varyasyonlarını azaltması yol açmıştır.

- Kaplama işlemi ile zemin kumaşların kopma mukavemeti artış göstermiştir. Kumaşa nüfuz eden kaplama maddesi, çözgü ve atk1 ipliklerinin hareketini önleyerek ipliklerin aynı anda kopmasını sağlamış, bunun sonucu olarak kumaşın kopma mukavemetini artırmıştır.

- $\mathrm{Su}$ buharı direnci sonuçlarına bakıldığında zemin kumaşa göre kaplamalı kumaşların daha az geçirgen olduğu tespit edilmiştir. Kaplama işlemi kumaş gözenekliliğini düşürdüğü için su buharı direnci de bu durumdan olumsuz etkilenmiştir. Hidrofil yapıda olan bir kaplama yüzeyi su buharı geçirgenliğini arttırabiliyorken çalışmada kullanılan kaplama malzemesinin yapısı su buharı geçirgenliğini düşürmüştür.

- Kaplama materyali kumaşa nüfuz ettiği için kaplama işlemi kumaşın yumuşaklığını önemli derecede etkilemektedir. Kaplamalı kumaşların sertliği artmıştır. Bu durum da beklenen bir sonuçtur.

- Aşınma dayanımı 50.000 devir'e kadar etkilenmemiştir.

- Polimer yapılı kaplama malzemesi kullanılması sonucu olarak boncuklanma dayanımı artmıştır.

\section{KAYNAKLAR}

1. Fung, W., 2002. Coated and Laminated Textiles, The Textile İnstitue, Woodhead Publishing Limited, England.

2. Bulut, Y., 2010. Kaplamalı Giysilik Kumaşların Mekanik Özellikleri Yüksek Lisans Tezi, Dokuz Eylül Üniversitesi, Fen Bilimleri Enstitüsü, İzmir, 110.

3. Öner, E., 2006. Tekstilde Kaplama, Tekstil Terbiye Teknolojisi Ders Notları, Marmara Üniversitesi, Teknik Eğitim Fakültesi, İstanbul.

4. Kut, D., Güneşoğlu, C., 2005. Poliüretan ve Poliakrilat Kaplanmış Kumaşların Performans Özelliklerinin Karşılaştırılması, TekstilMaraton Dergisi, 5: 62-65.

5. Sen, A.K., Damewood, J., 2001. Coated Textiles: Principles and Applications, 
(Illustrated Edition). USA: Technomic Publishing Company.

6. Kaplan, E., Koç, E., 2007. Kumaş Kaplama Teknikleri ve Kaplanmış Kumaş Özelliklerinin İncelenmesi, II. Tekstil Teknolojileri ve Tekstil Makinalar1 Kongresi, TMMOB Makina Mühendisleri Odas1, Gaziantep, 1-11.

7. Yesilalan, H.E., Warner, S.B., Laoulache, R., 2010. Penetration of Blade-Applied Viscous Coatings into Yarns in a Woven Fabric, Textile Research Journal, 80(18), 19301941.

8. Padleckiene, I., Petrulis, D., 2009. Effect of Abrasion on Theair Permeability \& Mass Loss of Breathable-Coated Fabrics, Fibres\&Textiles in Eastern Europe, 17(2-73), 50-54.

9. Şahin, B., 2005. Yüzey Kaplama Uygulama Tekniklerinin Farklı Materyallere Uygulanması ve Etkileri, Yüksek Lisans Tezi, Marmara Üniversitesi, Fen Bilimleri Enstitüsü, İstanbul, 126.

10. Yang, F., YU, W-D., 2006. Study on Mechanical Properties of PU Coated Fabric, International Forum on Textile Science and Engineering for Doctoral Candidates.

11.TS 251, 2002. Dokunmuş Kumaşlar Birim Alan Kütlesinin Tayini. Türk Standartları Enstitüsü, Ankara.

12. TS 7128 EN ISO 5084, 1998. Tekstil ve Tekstil Mamullerinin Kalınlık Tayini. Türk Standartları Enstitüsü, Ankara.

13.TS EN 250 ISO 1049-2, 1996. Tekstil Dokunmuş Kumaşlar Yap1 Analiz Metodlar1Kısım 2-Birim Uzunluktaki İplik Sayısının Tayini. Türk Standartları Enstitüsü, Ankara.

14. TS EN ISO 11092, 2014. Tekstil-Fizyolojik Özelliklerin Tayini-Kararlı Şartlarda Isıl Direncin ve Su Buharına Karşı Direncin Ölçülmesi (buğuya karşı korunmuş kızgın plaka deneyi), Türk Standartları Enstitüsü, Ankara.

15. ASTM D4032-94 Standard Test Method for Stiffness of Fabric by the Circular Bend Procedure.

16. TS EN ISO 12947-2, 2001. Tekstil-Martindale Metoduyla Kumaşların Aşınmaya Karşı Dayanımının Tayini-Bölüm 2: Numune Kopmasının Tayini, Türk Standartları Enstitüsü, Ankara.
17.TS EN ISO 12945-2, 2002. TekstilKumaşlarda Yüzey Tüylenmesi ve Boncuklanma Yatkınlığının Tayini- Bölüm 2: Geliştirilmiş Martindale Metodu, Türk Standartları Enstitüsü, Ankara.

18. TS EN ISO 13934-1, 2002. Tekstil-Kumaşların Gerilme Özellikleri-Bölüm 1: En Büyük Kuvvetin ve En Büyük Kuvvet Altında Boyca Uzamanın Tayini-Şerit Metodu, Türk Standartları Enstitüsü, Ankara. 
